\title{
$\alpha$ - and $\beta$-Adrenergic Receptor Mechanisms in Spontaneous Contractile Activity of Rat Ileal Longitudinal Smooth Muscle
}

\author{
Roland Seiler, B.A., Andreas Rickenbacher, B.A., Sidney Shaw, Ph.D., \\ Bruno M. Balsiger, M.D.
}

\begin{abstract}
Gastrointestinal motility is influenced by adrenergic modulation. Our aim was to identify specific subtypes of adrenergic receptors involved in inhibitory mechanisms that modulate gut smooth muscle contractile activity. Muscle strips of rat ileal longitudinal muscle were evaluated for spontaneous contractile activity and for equimolar dose-responses $\left(10^{-7}\right.$ to $\left.3 \times 10^{-5} \mathrm{M}\right)$ to the adrenergic agents norepinephrine (nonselective agonist), phenylephrine ( $\alpha_{1}$-agonist), clonidine ( $\alpha_{2}$-agonist), prenalterol ( $\beta_{1}$-agonist), ritodrine $\left(\beta_{2^{-}}\right.$ agonist), and ZD7114 ( $\beta_{3}$-agonist) in the presence and absence of tetrodotoxin (nonselective nerve blocker). Norepinephrine $\left(3 \times 10^{-5} \mathrm{M}\right)$ inhibited $65 \pm 6 \%$ (mean \pm SEM) of spontaneous contractile activity. The same molar dose of ritodrine, phenylephrine, or ZD7114 resulted in less inhibition (46 $\pm 7 \%$, $31 \pm 5 \%$, and $39 \pm 3 \%$, respectively; $P<0.05$ ). The calculated molar concentration of ZD7114 needed to induce $50 \%$ inhibition was similar to that of norepinephrine, whereas higher concentrations of phenylephrine or ritodrine were required. Clonidine and prenalterol had no effect on contractile activity. Blockade of intramural neural transmission by tetrodotoxin affected the responses to ritodrine and phenylephrine (but not to norepinephrine or ZD7114), suggesting that these agents exert part of their effects via neurally mediated enteric pathways. Our results suggest that adrenergic modulation of contractile activity in the rat ileum is mediated primarily by muscular $\beta_{3^{-}}, \beta_{2^{-}}$, and $\alpha_{1}$-receptor mechanisms; the latter two also involve neural pathways. (J GASTROINTEST Surg 2005;9:227-235) (c) 2005 The Society for Surgery of the Alimentary Tract
\end{abstract}

KeY WORDS: Contractility, motility, ileum, rat, in vitro, adrenergic, adrenergic receptor, $\alpha$-adrenergic receptors, $\beta$-adrenergic receptors

Coordination and modulation of gastrointestinal motor activity are dependent on the interaction of two complex neural inputs: the enteric nervous system, which is completely intrinsic within the bowel wall, and the central nervous system, sending its influences through the extrinsic nerves to the gut (vagal, sympathetic). ${ }^{1}$ Interactions between the central nervous system and the enteric nervous system are important in gastrointestinal responses to stress, eating, and behavior. $^{2}$

Vagal motor pathways modulate mainly the upper gastrointestinal tract and the distal colon and rectum.
In the small bowel, vagal inputs are supplied to myenteric neurons. ${ }^{3}$ These enteric neurons influence the generation of motor patterns.

The intestinal sympathetic nervous system consists of nerve cell bodies located in the prevertebral ganglia with their postganglionic fibers entering the gut. No adrenergic nerve cell bodies are present in the gut wall. ${ }^{1}$ Most, if not all, sympathetic postganglionic fibers affecting motility are thought to synapse in the enteric nervous system and not directly on smooth muscle cells. Indeed, adrenergic nerves do not synapse directly on nonsphincter muscle cells in the gut. ${ }^{4}$

Presented in part at the Forty-Third Annual Meeting of The Society for Surgery of the Alimentary Tract, San Francisco, California, May 19-22, 2002 (poster presentation).

From the Gastroenterology Unit (R.S., A.R., B.M.B.) and the Department of Clinical Research (R.S., A.R., S.S., B.M.B.), University of Bern, Bern, Switzerland.

Supported by Nycomed AG Switzerland, Ethicon, Switzerland, and the Swiss National Science Foundation (B.M.B.; Nr. 31-61583.00). Reprint requests: Dr. Balsiger, Gastroenterology Unit and Dept. of Clinical Research, University of Bern, Tiefenaustrasse 120, 3004 Bern, Switzerland. e-mail: bruno.balsiger@dkf.unibe.ch 
Despite the predominant, direct adrenergic input to the enteric nervous system, we found strong, adrenergically mediated inhibitory motor mechanisms in rat jejunum and ileum occurring preferentially at the level of these smooth muscle cells rather than in the enteric nervous system ${ }^{5,6}$; these effects appeared to be independent of input from the enteric nervous system.

Therefore, one approach to target gastrointestinal motility disorders through adrenergic pathways would be to direct the pharmacologic therapy at the receptors occurring in the gut on smooth muscle cells. To date, therapeutic approaches targeting adrenergic pathways in the gastrointestinal tract have not been very successful, in part because of substantial cardiovascular side effects of the agents used. ${ }^{7}$

Therefore, mechanisms involved in modulating contractile activity of the gut mediated by specific subtypes of adrenergic receptors are of considerable interest. Our first aim was to identify which adrenergic receptor subtypes mediate inhibition of spontaneous contractile activity. Second, we wanted to determine if these receptor-specific mechanisms were mediated at the level of the smooth muscle and/or via the enteric nervous system. Our hypothesis was that both $\alpha_{1}$ - and $\beta_{2}$-receptor mechanisms mediate the inhibitory responses and that these mechanisms are active directly at the level of the smooth muscle and not indirectly via effects mediated through the enteric nervous system.

\section{METHODS}

\section{Preparation of Tissue}

Procedures and animal care were performed according to the guidelines of the Department of Agriculture of the Canton of Bern, Switzerland. Male Wistar rats were used in all experiments. Anesthesia was achieved with intraperitoneal sodium pentobarbital (5 mg/100 g; Abbott Laboratories, North Chicago, IL). A 5 -cm segment of the ileum was removed beginning $2 \mathrm{~cm}$ orad to the ileocecal valve and stored in cold Krebs-Ringer buffer (concentration in $\mathrm{mM}: \mathrm{NaCl}$ 118.3, $\mathrm{KCl}$ 4.7, $\mathrm{CaCl}_{2} 2.5, \mathrm{MgSO}_{4} 1.2, \mathrm{KH}_{2} \mathrm{PO}_{4} 1.2$, $\mathrm{NaHCO}_{3} 25.0$, calcium disodium edetate 0.26 , and glucose 11.1). The distal end of the specimen was marked.

\section{Recording of Contractile Activity}

The segment of the distal ileum was immersed in chilled, modified Krebs-Ringer bicarbonate solution and opened along the mesenteric border. The tissue was pinned flat in a Petri dish, and eight full-thickness muscle strips per rat were prepared in the direction of the longitudinal muscle. Silk loops were tied at both ends of the strips. The muscles were suspended vertically in 5-ml organ chambers (Radnoti Glass Technology Inc., Monrovia, CA) filled with modified Krebs-Ringer bicarbonate solution maintained at $37.5^{\circ} \mathrm{C}$ and bubbled with $95 \% \mathrm{O}_{2}$ and $5 \%$ $\mathrm{CO}_{2}$ (Carbagas, Bern, Switzerland). The lower end of the muscle strip was connected to a fixed glass hook in the chamber, and the upper end was attached to a noncompliant force transducer (Radnoti Glass Technology Inc.), thereby allowing measurement of isometric force.

\section{Experimental Design}

After an equilibration period of 80-90 minutes with change of the buffer solution every 20-25 minutes, each strip was stretched incrementally at 10- to 15minute intervals to its optimal length $\left(\mathrm{L}_{\mathrm{o}}\right)$. $\mathrm{L}_{\mathrm{o}}$ is defined as the length beyond which further stretching did not increase the amplitude of spontaneous contractions. The entire experiment was then performed at this $\mathrm{L}_{\mathrm{o}}$; strips without spontaneous activity were not used ( $2 \%$ of all muscle strips).

After recording of baseline spontaneous activity, one substance was administered per chamber in a cumulative manner every 10 minutes. Norepinephrine $(\mathrm{NE})$ was chosen as the nonselective adrenergic agonist; phenylephrine and clonidine as $\alpha_{1-}$ and $\alpha_{2}-$ selective agonists; and prenalterol, ritodrine, and ZD7114, as $\beta_{1^{-}}, \beta_{2^{-}}$, and $\beta_{3^{-}}$-selective agonists, respectively. Drugs were added in cumulative doses $\left(10^{-7}\right.$ to $3 \times 10^{-5} \mathrm{M}$ ) every 10 minutes. The highest dose used was $3 \times 10^{-5} \mathrm{M}$ according to our previous work using only NE. ${ }^{5,6}$ One chamber contained a control strip to confirm stable activity during the duration of the experiment, and the final chamber contained a spare strip.

After the dose-response experiment, the chambers were washed 4 times with modified Krebs-Ringer buffer. When spontaneous contractions returned to baseline activity, tetrodotoxin (TTX; $10^{-6} \mathrm{M}$ ) was added to every chamber. TTX is thought to abolish most all enteric neural input by blocking neuronal sodium channels. After a 15 - to 20 -minute equilibration, the same dose-response experiment was repeated in each chamber with the same agonist.

At the conclusion of the experiment, the length of each strip between the two ties of silk loops and wet weight was measured.

\section{Data Analysis}

Total spontaneous contractile activity was quantified as the integral of the generated force $(g \times$ time as total area under the contractile curve) measured 
for 5 minutes at $\mathrm{L}_{\mathrm{o}}$, whereas responses to adrenergic agonists were quantified by measuring the integral of force for 5 minutes immediately after drug administration. The integral of force was calculated by computerized methodology using special software (AcqKnowledge, Biopac Systems, Inc., Goleta, CA), normalized per millimeter squared of cross-sectional area (CSA) for each muscle strip.

The CSA was calculated using the following equation:

CSA $\left(\mathrm{mm}^{2}\right)=$ Tissue wet weight $(\mathrm{mg}) /$ Tissue length $(\mathrm{mm}) \times$ Tissue density $\left(\mathrm{mg} / \mathrm{mm}^{3}\right)$

Tissue length and weight were measured at the end of the experiment, and smooth muscle tissue density was assumed to be $1.05 \mathrm{mg} / \mathrm{mm}^{3,8}$

The dose-response curve for each agonist was obtained by defining spontaneous contractile activity as $100 \%$. To quantify these dose-response curves, the negative of the natural $\log (\mathrm{In})$ of the equipotent concentration that caused a $50 \%$ response $\left(\mathrm{EC}_{50}\right)$ was estimated for each agonist based on the dose-response curve. A greater $\mathrm{EC}_{50}$ represents a smaller concentration of an agonist needed to induce $50 \%$ inhibition of spontaneous activity.

Values are presented as mean \pm SEM. Student's $t$ tests with a Bonferroni correction were used to compare the effects of each specific agonist with spontaneous activity at all doses and with the respective effect of NE. The effect of TTX on spontaneous activity, on $\mathrm{EC}_{50}$, and on each dose of the respective agonist was evaluated in the same way.

\section{Drugs}

L-Phenylephrine hydrochloride, clonidine hydrochloride, ritodrine hydrochloride, and norepinephrine bitartarate salt were purchased from Sigma (St. Louis, MO). Prenalterol and ZD7114 hydrochloride were purchased from Astra Zeneca (Södertälje, Sweden). TTX was purchased from Juro (Luzern, Switzerland).

A

Norepinephrine
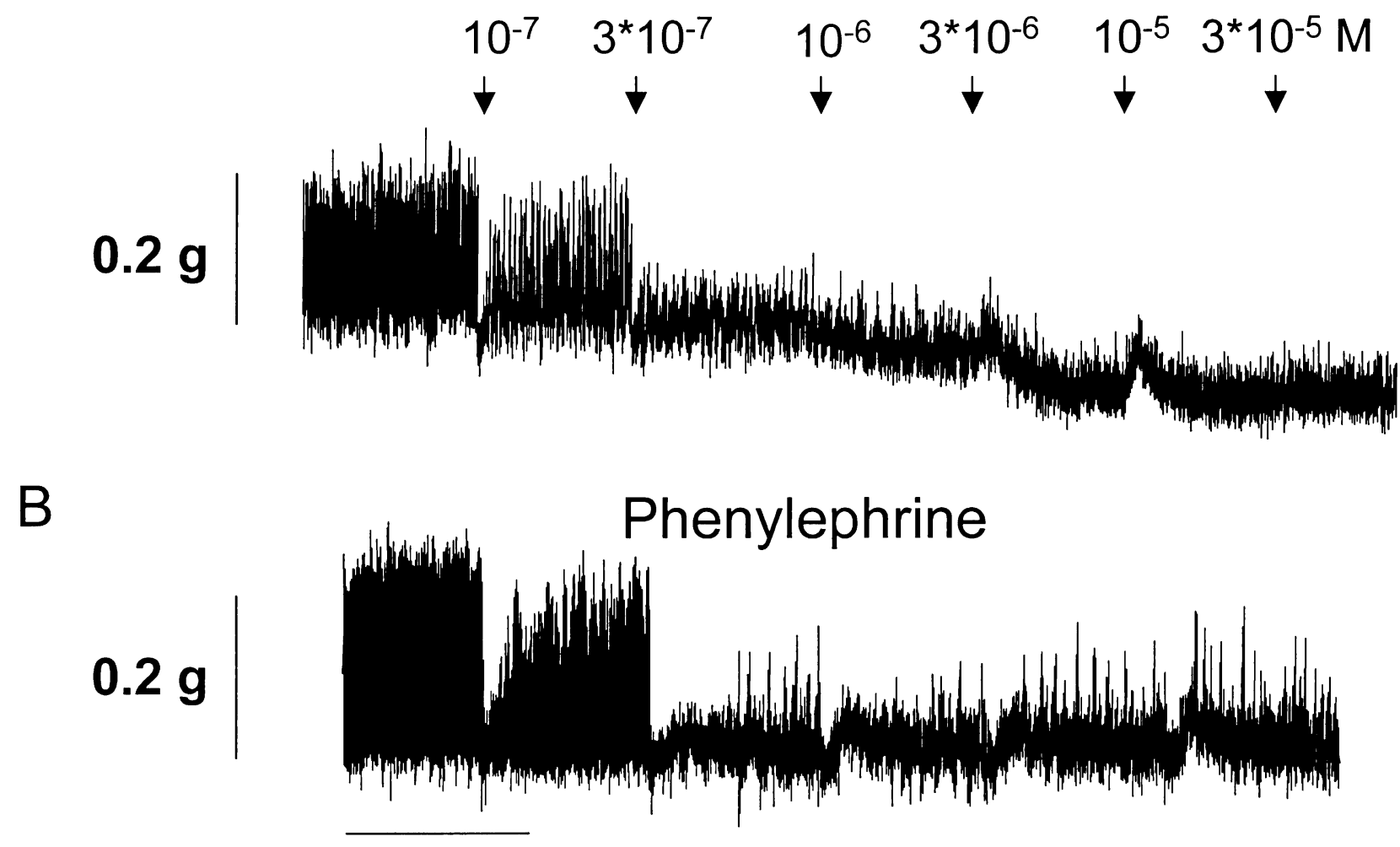

$10 \mathrm{~min}$

Fig. 1. Effect of norepinephrine (A) and phenylephrine $\left(\alpha_{2}\right)(\mathbf{B})$ on spontaneous activity. Cumulatively administered molar doses of agents caused a dose-dependent decrease in contractile activity. 


\section{RESULTS}

\section{Spontaneous Contractile Activity}

Spontaneous phasic contractile activity was recorded shortly after suspending the muscle strips in the organ chambers. After the addition of TTX (after the first adrenergic dose-response experiments, washout, and restoration of spontaneous activity), contractile activity was reduced slightly from $77 \pm 8$ to $73 \pm 8\left(\mathrm{~g} / 5 \mathrm{~min} / \mathrm{mm}^{2} ; P<0.01\right)$.

\section{Effect of Nonselective Adrenergic Stimulation}

In all strips treated with NE, the amplitude and the baseline tone were reduced in a dose-dependent manner, whereas the frequency of contractions remained unchanged. At the higher doses, an initial increase in basal tone was observed (Fig. 1A). Inhibition of spontaneous contractile activity induced by the highest dose of norepinephrine $\left(3 \times 10^{-5} \mathrm{M}\right)$ was $65 \pm 6 \%$. Blocking all neural activity within the bowel wall with TTX $\left(10^{-6} \mathrm{M}\right)$ did not change the doseresponse to NE (Table 1) nor the effect of the highest dose of NE on baseline tone (Table 2).

\section{Effect of $\alpha$-Agonists}

Phenylephrine ( $\alpha_{1}$-agonist) inhibited contractile activity by reducing the amplitude but not the basal tone in a dose-dependent fashion (Fig. 1B). However, the $\mathrm{EC}_{50}$ was less than that for $\mathrm{NE}$, and the inhibition (at $3 \times 10^{-5} \mathrm{M}$ ) was less compared with an equimolar dose of norepinephrine (Table 1; Figs. 1, 2A). TTX had no effect on $\alpha_{1}$-receptor-mediated inhibition induced by phenylephrine. However, if only changes in baseline tone were analyzed, TTX slightly increased the change of baseline tone induced by the highest dose of phenylephrine $\left(3 \times 10^{-5} \mathrm{M} ; 35 \pm 5 \%\right.$
Table 2. Reduction of baseline tone induced by adrenergic agonist without or with tetrodotoxin (TTX; $\left.10^{-6} \mathrm{M}\right)$

\begin{tabular}{lcc}
\hline & \multicolumn{2}{c}{ Response to $\mathbf{3} \times \mathbf{1 0}^{-\mathbf{5}} \mathbf{M}$ dose $^{*}$} \\
\cline { 2 - 3 } & Without TTX & With TTX \\
\hline Norepinephrine & $75 \pm 9$ & $80 \pm 6$ \\
Phenylephrine, $\alpha_{1}$ & $35 \pm 5$ & $43 \pm 4^{\dagger}$ \\
Clonidine, $\alpha_{2}$ & $7 \pm 4$ & $20 \pm 4$ \\
Prenalterol, $\beta_{1}$ & $26 \pm 4$ & $32 \pm 6$ \\
Ritodrine, $\beta_{2}$ & $66 \pm 8$ & $45 \pm 6^{\dagger}$ \\
ZD7114, $\beta_{3}$ & $58 \pm 7$ & $60 \pm 7$ \\
\hline
\end{tabular}

*Values represent percent (mean $\pm \mathrm{SEM} ; \mathrm{n} \geqslant 8$ rats) reduction of baseline (one after the highest dose of agonist $\left(3 \times 10^{-5} \mathrm{M}\right)$ compared with baseline tone before dose-response experiment (100\%).

${ }^{\dagger} P<0.05$ compared with without TTX.

versus $43 \pm 4 \%, P<0.05$; Table 2$)$. Clonidine $\left(\alpha_{2}\right.$-agonist $)$ with and without TTX had no demonstrable effect on contractile activity.

\section{Effect of $\boldsymbol{\beta}$-Agonists}

Differing effects of the three $\beta$-adrenergic agonists were noted. Prenalterol ( $\beta_{1}$-agonist) with or without TTX had no effect. In contrast, ritodrine $\left(\beta_{2}\right.$-agonist) and ZD7114 ( $\beta_{3}$-agonist) both induced a marked, dose-dependent effect with inhibitions of $39 \pm 3 \%$ and $46 \pm 7 \%$ at $3 \times 10^{-5} \mathrm{M}$ doses, respectively (Table 1, Figs. 2B, 3). TTX did not influence the dose-response of ZD7114 ( $\beta_{3}$-agonist), but TTX reduced the inhibitory effect of $3 \times 10^{-5} \mathrm{M}$ ritodrine ( $\beta_{2}$-agonist $)$ from $46 \pm 7 \%$ to $35 \pm 6 \%(P<0.05)$; the $\mathrm{EC}_{50}$, however, did not change (Table 1). This decrease in inhibition seems to be due primarily to a lesser reduction in the basal tone (Fig. 4). Ritodrine $\left(3 \times 10^{-5} \mathrm{M} ; \beta_{2}\right.$-agonist) reduced basal tone by

Table 1. Inhibitory effect of selective adrenergic agonists on rat ileal longitudinal muscle without and with tetrodotoxin (TTX; $10^{-6} \mathrm{M}$ )

\begin{tabular}{|c|c|c|c|c|}
\hline & \multicolumn{2}{|c|}{ Response to $3 \times 10^{-5} \mathrm{M}$ dose* } & \multicolumn{2}{|c|}{$\mathrm{EC}_{50}$} \\
\hline & Without TTX & With TTX & Without TTX & With TTX \\
\hline Norepinephrine & $65 \pm 6^{\dagger}$ & $70 \pm 5^{\dagger}$ & $5 \pm 0.3$ & $5.3 \pm 0.7$ \\
\hline Phenylephrine, $\alpha_{1}$ & $31 \pm 5^{\dagger \ddagger}$ & $30 \pm 6^{\dagger \ddagger}$ & $1.5 \pm 0.7^{\ddagger}$ & $2.3 \pm 1.2^{\ddagger}$ \\
\hline Clonidine, $\alpha_{2}$ & $5 \pm 3^{\ddagger}$ & $13 \pm 7^{\ddagger}$ & NA & NA \\
\hline Prenalterol, $\beta_{1}$ & $9 \pm 4^{\ddagger}$ & $15 \pm 2^{\dagger \ddagger}$ & NA & NA \\
\hline Ritodrine, $\beta_{2}$ & $46 \pm 7^{\dagger \ddagger}$ & $35 \pm 6^{\dagger \ddagger \S}$ & $3.5 \pm 0.4^{\ddagger}$ & $3.0 \pm 0.6^{\ddagger}$ \\
\hline $\mathrm{ZD} 7114, \beta_{3}$ & $39 \pm 3^{\dagger \neq}$ & $42 \pm 4^{\dagger \ddagger}$ & $4.4 \pm 0.6$ & $4.4 \pm 0.4$ \\
\hline
\end{tabular}




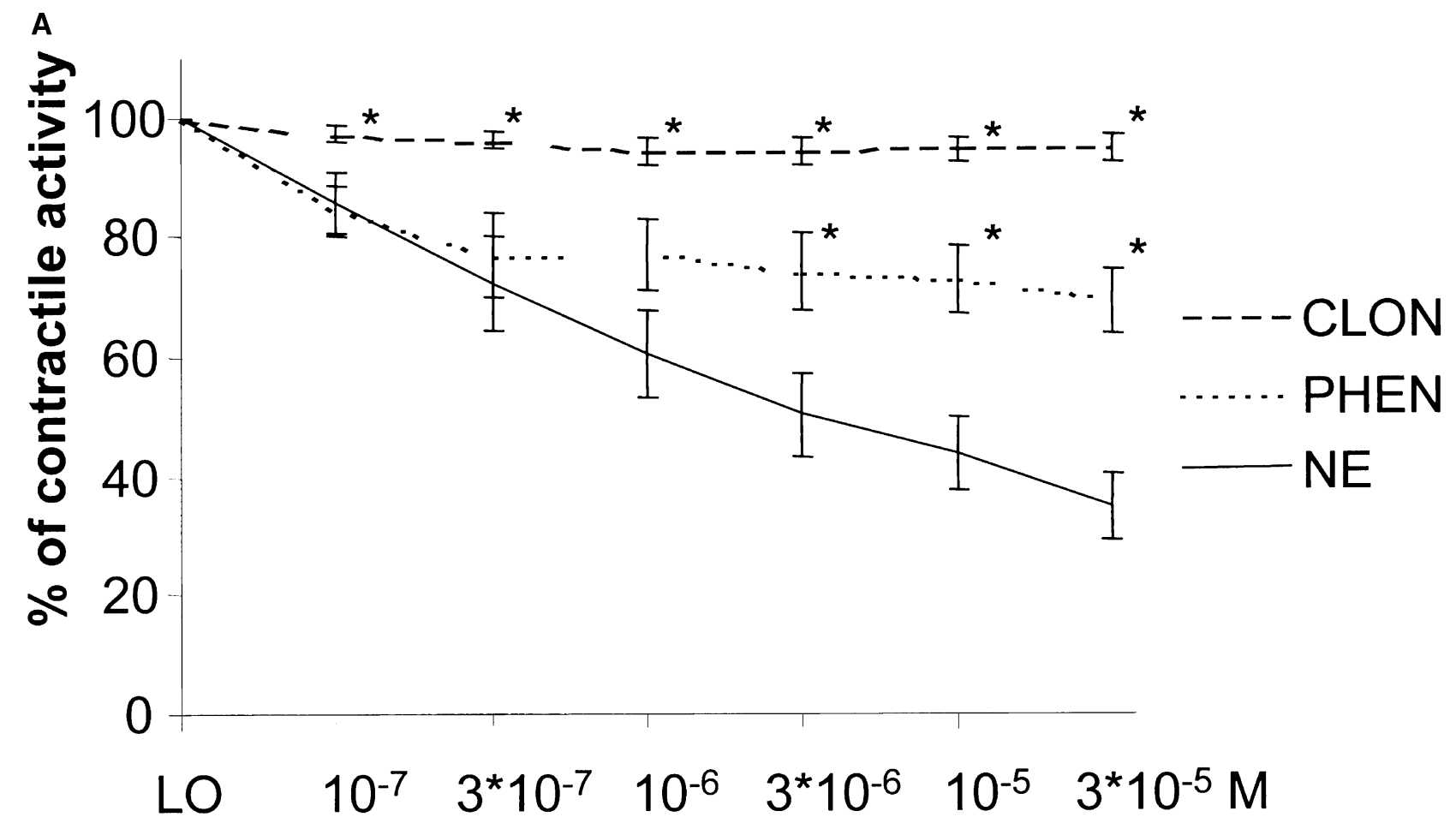

Concentration of $\alpha$-adrenergic agonists

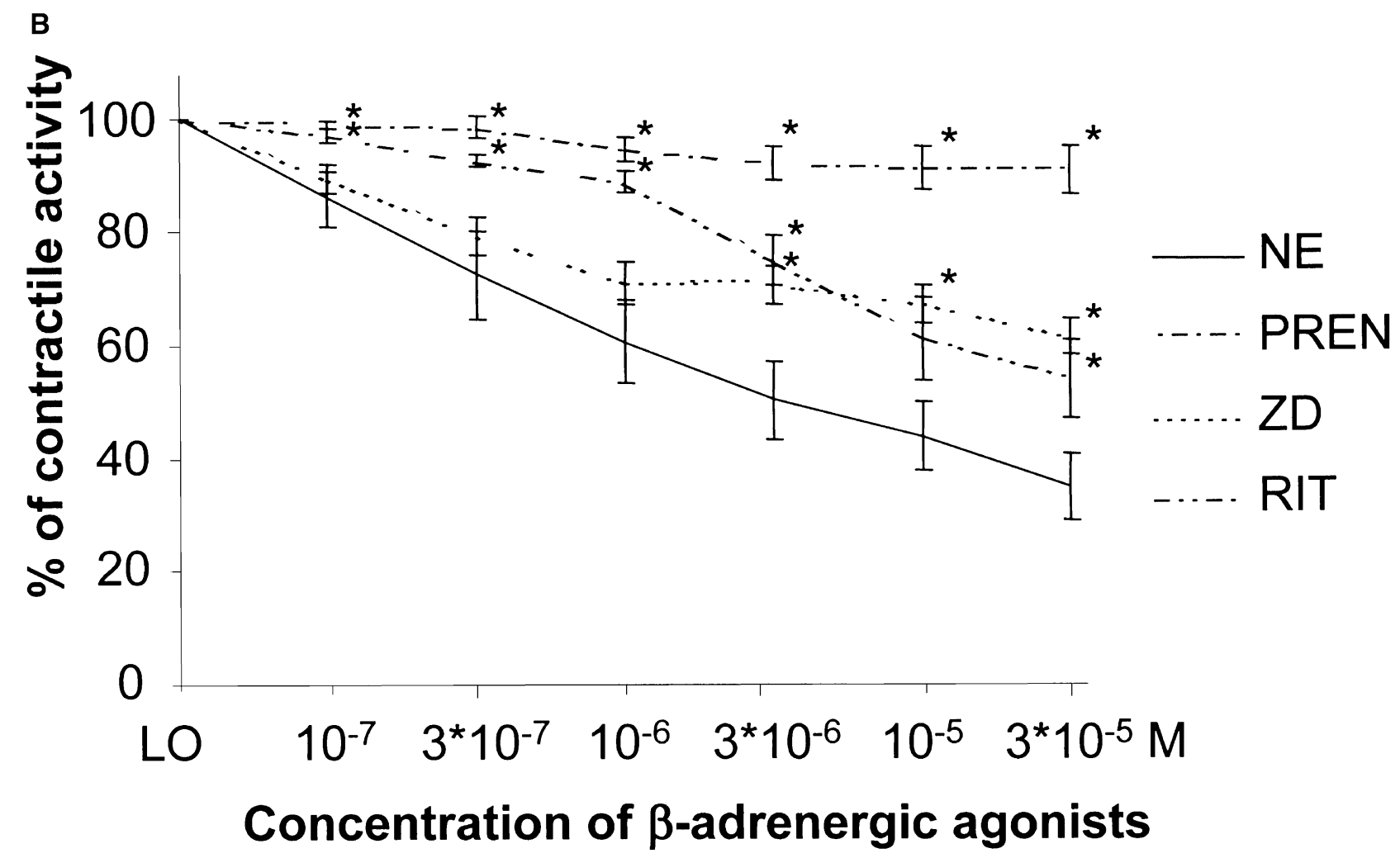

Fig. 2. Dose-responses of (A) clonidine (CLON) $\left(\alpha_{1}\right)$ and phenylephrine (PHEN) $\left(\alpha_{2}\right)$ and of $(\mathbf{B})$ prenalterol (PREN) $\left(\beta_{1}\right)$, ritodrine (RIT) $\left(\beta_{2}\right)$ and ZD7114 (ZD) $\left(\beta_{3}\right)$ compared with norepinephrine (NE). Values given as mean \pm SEM; $\mathrm{n}=9$ rats. ${ }^{*} P<0.05$ versus $\mathrm{NE}$. 


\section{ZD7114}

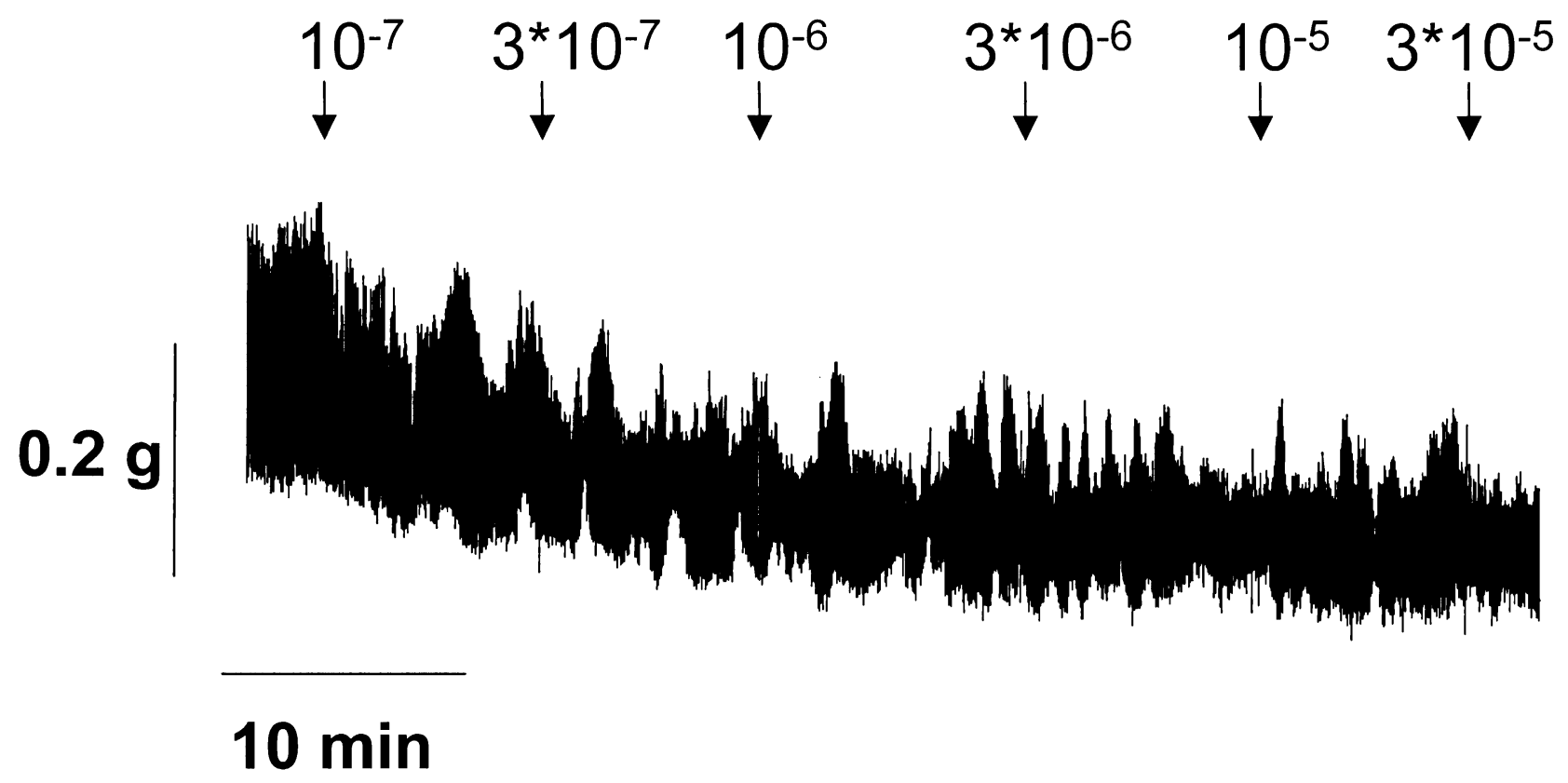

Fig. 3. Effect of ZD7114 $\left(\beta_{3}\right)$ on spontaneous activity. ZD7114 was administered cumulatively and caused a dose-dependent decrease in basal tone and thus in contractile activity.

$66 \pm 8 \%$. In the presence of TTX, the reduction in baseline tone was smaller $(45 \pm 6 \%, P<0.05)$.

The $\mathrm{EC}_{50}$ for ZD7114 did not differ from the $\mathrm{EC}_{50}$ of $\mathrm{NE}(4.4 \pm 0.6$ versus $5.0 \pm 0.3)$, suggesting a similar molar inhibitory effect by ZD7114. The $\mathrm{EC}_{50}$ of ritodrine and $\mathrm{NE}(3.5 \pm 0.4$ versus $5.0 \pm 0.3$, $P<0.05)$ differed; the dose-response curve for ritodrine was shifted to the right, compared with $\mathrm{NE}$ (Fig. 2B).

\section{DISCUSSION}

Our study was designed to characterize the involvement of specific adrenergic $\alpha_{1^{-}}, \alpha_{2^{-}}, \beta_{1^{-}}, \beta_{2^{-}}$, or $\beta_{3}$-receptor mechanisms in the inhibition of contractile activity of longitudinal smooth muscle in the rat ileum. These contractile responses are of particular interest, because modulation of gut motility via adrenergic pathways may represent a novel therapeutic target for motility disorders. This pharmacologic approach would require identification of specific receptor subtype mechanisms such that effects on intestinal contractile function can be targeted, possibly minimizing or even avoiding cardiovascular side effects.
Our main findings were that $\alpha_{2}$ - and $\beta_{1}$-receptor mechanisms do not appear to be involved in the adrenergic modulation of gut contractile activity in the rat, neither directly on the smooth muscle cells nor indirectly via the enteric nervous system. In contrast, $\alpha_{1}$, $\beta_{2}$, and $\beta_{3}$ pathways reproduced, in part, the inhibition induced by norepinephrine, a nonselective, global adrenergic agonist. Blocking enteric neural activity within the muscle strip (with TTX $10^{-6} \mathrm{M}$ ) partially reduced the response of $\beta_{2}$-receptor and slightly increased the response of $\alpha_{1}$-receptor stimulation, suggesting involvement of enteric neural mechanisms.

The involvement of $\alpha_{1}$ - but not $\alpha_{2}$-receptors in the control of motor activity in the rat ileum is of special interest, because in general not much is known about the role of $\alpha$-receptors in intestinal contractility. A case report of a patient with pheochromocytoma in whom paralytic ileus was treated successfully with the $\alpha$-receptor antagonist phentolamine and later with prazosin (selective $\alpha_{1}$-receptor agonist $)^{9}$ suggests that $\alpha$-mechanisms may be involved in human small bowel contractile activity, whereas in an in vitro study in human tissue, $\alpha_{2}$ pathways did not seem to play a role. ${ }^{10}$ Therefore, it seems likely that in control of human small bowel contractility, $\alpha$-adrenergic influence is dependent on $\alpha_{1}$-receptors. This would be in accordance with our 

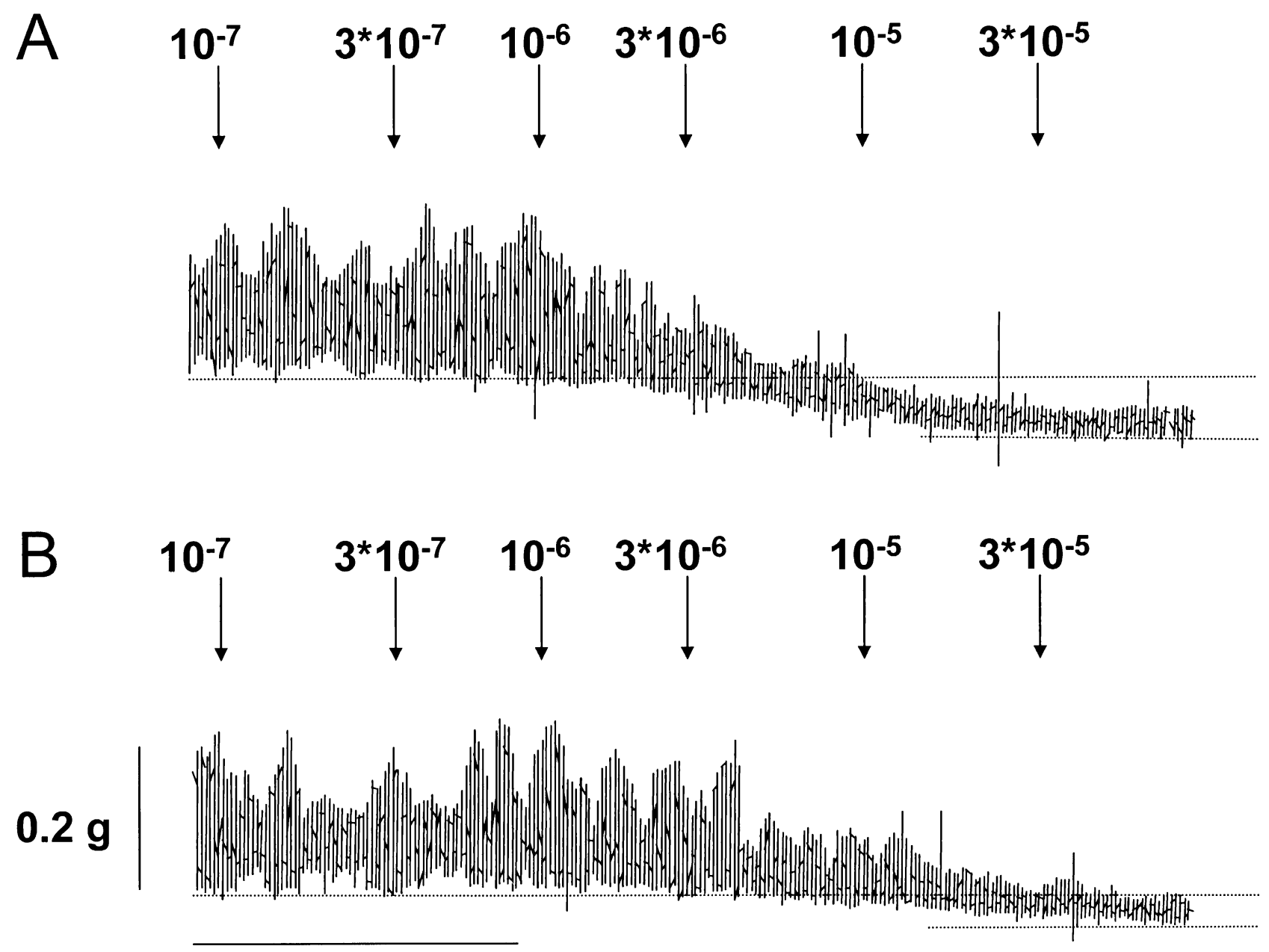

\section{$20 \mathrm{~min}$}

Fig. 4. (A) Effect of ritodrine $\left(\beta_{2}\right)$ on spontaneous activity. Ritodrine was administered cumulatively and caused a dose-dependent decrease in contractile activity. (B) In presence of tetrodotoxin, the dosedependent reduction in basal tone was smaller, thus reducing the overall inhibitory effect induced by ritodrine.

results in rat ileum where $\alpha_{1}$ mechanisms but not $\alpha_{2}$ pathways appear to influence contractile properties in vitro. However, in the gut of other species, the role of $\alpha$-receptors is different: in guinea pig ileum, both $\alpha_{1}$ - and $\alpha_{2}$-receptors mediate inhibition, ${ }^{11}$ and in canine and mouse ileum and in rat colon, only $\alpha_{2}$, not $\alpha_{1}$, inhibitory mechanisms have been described. ${ }^{12-14}$ In rabbit, $\alpha_{1}$ mechanisms can be part of inhibitory pathways in other anatomic regions of the gut such as jejunum ${ }^{15}$ and duodenum. ${ }^{16}$ Because of marked species differences, broad generalizations between species must be made with caution.

Inhibitory mechanisms mediated by $\beta_{2}$-adrenergic receptors were identified in our study. This finding is consistent with results in rabbit ileum, ${ }^{17}$ whereas in canine ileum, $\beta_{2}$ pathways had no influence on contractile activity. ${ }^{12}$
$\beta_{3}$-Receptors have been of particular interest because they seem to be abundantly present in gastrointestinal tissue. ${ }^{18,19}$ Our results are in accordance with the data of Brown and Summers, ${ }^{20}$ who showed that $\beta_{3}$ pathways play a major role in the inhibition of rat ileum. In guinea pig ileum, contractile activity is also inhibited by $\beta_{3}$-receptor stimulation, ${ }^{21}$ whereas canine ileum does not seem to be influenced by $\beta_{3^{-}}$ receptors. $^{12}$

As discussed earlier, $\beta_{2}$ - and $\beta_{3}$-receptor-specific inhibition plays a role in inhibiting contractile activity, whereas $\beta_{1}$-receptor mechanisms do not appear to be involved in the inhibition of longitudinal muscle of the rat ileum. Our latter finding contrasts with data from Brown and Summers, ${ }^{20}$ who reported a slight effect of $\beta_{1}$-receptor mechanisms in rat ileum. Differences in the muscle layers investigated and in 
the experimental protocols, such as different substances that were used and conduction of the experiment in precontracted muscle strips, may explain some of these differences. We have shown previously that different contractile responses in circular versus longitudinal muscle layers are as important as are differences between anatomic regions of jejunum versus ileum. ${ }^{22,23}$ In an in vivo study in canine ileum that supports our results, $\beta_{1}$-receptors were found to not be important. ${ }^{12}$

In our experiments, we tried to distinguish between muscle-related mechanisms and pathways involving the enteric nervous system, because under pathologic conditions, adrenergic mechanisms might be compromised at either level of control. ${ }^{5,24,25}$ None of the specific adrenergic $\alpha_{2^{-}}, \beta_{1^{-}}$, or $\beta_{3}$-receptor mechanisms were TTX sensitive, and therefore the pathways seem to be independent of the enteric nervous system. Interestingly, part of the $\beta_{2}$ and $\alpha_{1}$ inhibition in our experiments appears to be modulated by presynaptic mechanisms. Blockade of neural $\beta_{2}$ mechanisms by TTX resulted in a lesser inhibition of contractile activity. This neurally mediated effect appears to occur via a reduction in baseline tone rather than a reduction in phasic activity. In contrast, the $\alpha_{1}$-adrenergic effect appears to be related to a slight increase in baseline tone. The physiologic relevance of these findings as seen in our in vitro measurement of isometric contractions is not yet known. In other study designs, the distinction between muscle or neurally mediated inhibition was not made. ${ }^{17}$ However, it is conceivable that part of the gastrointestinal motility disorders in neurologic diseases such as diabetic neuropathy or other postneurotomy syndromes (e.g., postvagotomy gastroparesis) are linked with an impaired modulation of contractile activity via $\beta_{2}$ and $\alpha_{1}$ mechanisms. Thus, further studies are required.

\section{CONCLUSION}

Because none of the specific pathways alone reached the degree of inhibition achieved by NE, we conclude that adrenergic inhibition in rat ileum may be an additive effect of the three specific adrenergic mechanisms noted to inhibit contractile activity $\left(\alpha_{1}, \beta_{2}\right.$, and $\left.\beta_{3}\right)$. This concept of the involvement of several receptors in inhibitory mechanisms is supported by previous results in rabbit ileum ${ }^{17}$ and by studies in human colon by Manara et al. ${ }^{26}$ Possibly, the known plasticity of the gut may allow one receptor to take over for another receptor under various conditions. Hutchinson et al. ${ }^{27}$ showed that $\beta_{1}$-adrenoceptors may compensate for $\beta_{3}$-adrenoceptors in adrenoceptor-mediated relaxation of ileal muscle from $\beta_{3}$-adrenoceptor knock-out mice, and Susulic et al. ${ }^{28}$ Suggest that "cross-talk" might exist between $\beta_{3}$-adrenoceptors and $\beta_{1}$-adrenoceptor gene expression.

Our results, when compared with the literature, underline the high degree of variability not only in regional dependent differences (anatomic and muscle layer) but also between species. It is of interest that $\alpha_{1}$-receptor mechanisms (but not $\alpha_{2}$ pathways) played a role in our rat ileum study. The scarce data from the literature suggest a similar constellation of contractile $\alpha$ mechanisms in human small bowel. If this similarity is confirmed in the future, the rat ileum might be attractive to further model $\alpha_{1}$ pathways in pathologic states.

For $\beta_{2^{-}}$and $\beta_{3}$-receptors, species differences are evident as well, but we do not have comparable data for human ileum. Species differences, especially for $\beta_{3}$ pathways, would be of interest, because these receptors are abundantly present not only in adipose tissue but also in gastrointestinal tissue and therefore are of interest for the study of gastrointestinal motility. ${ }^{29,30}$ To our knowledge the role of $\beta_{3}$-receptors in human contractility has not been carefully investigated in vitro.

Because of the species differences of adrenoceptor distribution and function, choosing the right animal model is crucial. This has been noted for cardiovascular studies ${ }^{17}$ and will be the same for contractile studies of the gastrointestinal tract.

The authors thank Dr. M. G. Sarr for bis valuable input to the manuscript.

\section{REFERENCES}

1. Goyal RK, Hirano I. Mechanisms of disease: The enteric nervous system. N Engl J Med 1996;334:1106-1115.

2. Tache $\mathrm{Y}$, Monnikes H. CRF in the central nervous system mediates stress induced stimulation of colonic motor function: Relevance to the pathophysiology of IBS. In Mayer EA, Raybould HE, eds. Basic and Clinical Aspects of Chronic Abdominal Pain. Amsterdam: Elsevier, 1993, pp 141-151.

3. Kirchgessner AL, Gershon MD. Identification of vagal efferent fibers and putative target neurons in the enteric nervous system of the rat. J Comp Neurol 1989;285:38-53.

4. Johnson LR, Alpers DH, Christensen J, Jacobson ED, Walsh JH. Physiology of the Gastrointestinal Tract. 3rd ed. New York: Raven Press, 1994, pp 751-794.

5. Shibata C, Balsiger BM, Anding WJ, Sarr MG. Adrenergic denervation hypersensitivity in ileal circular smooth muscle after small bowel transplantation in rats. Dig Dis Sci 1997; 42:2213-2221.

6. Ohtani N, Balsiger BM, Anding WJ, Duenes JA, Sarr MG. Small bowel transplantation induces adrenergic hypersensitivity in ileal longitudinal smooth muscle in rats. J Gastrointest Surg 2000;4:77-85.

7. Lyrenas E, Abrahamsson H, Dotevall G. Rectosigmoid motility response to beta-adrenoceptor stimulation in patients with 
the irritable bowel syndrome. Scand J Gastroenterol 1985; 20:1163-1168.

8. Gordon AR, Siegman MJ. Mechanical properties of smooth muscle. I. Length-tension and force-velocity relations. Am J Physiol 1971;221:1243-1249.

9. Sawaki D, Otani Y, Sekita G, Kobayakawa N, Fukushima K, Takeuchi H, Aoyagi T. Pheochromocytoma complicated with refractory paralytic ileus dramatically improved with intravenous administration of alpha-adrenergic receptor antagonist, phentolamine. J Clin Gastroenterol 2003;37:194.

10. Lepor H, Rigaud G, Shapiro E, Baumann M, Kodner IJ, Fleshman JW. Muscarinic cholinergic and alpha 2-adrenergic receptors in the epithelium and muscularis of the human ileum. Surgery 1990;107:461-467.

11. Martinolle JP, Garcia-Villar R, Fioramonti J, Bueno L. Altered contractility of circular and longitudinal muscle in TNBS-inflamed guinea pig ileum. Am J Physiol 1997;272: G1258-G1267.

12. Sakai Y, Daniel EE, Jury J, Fox JE. Neurotensin inhibition of canine intestinal motility in vivo via alpha-adrenoceptors. Can J Physiol Pharmacol 1984;62:403-411.

13. De Man JG, Moreels TG, De Winter BY, Bogers JJ, Van Marck EA, Herman AG, Pelckmans PA. Disturbance of the prejunctional modulation of cholinergic neurotransmission during chronic granulomatous inflammation of the mouse ileum. Br J Pharmacol 2001;133:695-707.

14. Decktor DL, Pendleton RG, Ensslen ME, Davis MM. Lidamidine inhibits intrinsic contractile patterns of the rat proximal colon. Eur J Pharmacol 1987;143:213-219.

15. Gater PR, Haylett DG, Jenkinson DH. Neuromuscular blocking agents inhibit receptor-mediated increases in the potassium permeability of intestinal smooth muscle. Br J Pharmacol 1985;86:861-868.

16. Wikberg JE. Reversal of alpha 1-receptor mediated relaxation in intestinal smooth muscle. Acta Physiol Scand 1981;111: 385-395.

17. Wagner J, Nick B, Rohm N, Schumann HJ. On the coexistence of beta 1 - and beta 2-adrenoceptors in various organs. Arch Int Pharmacodyn Ther 1981;249:26-38.

18. Manara L, Croci T, Landi M. Beta 3-adrenoceptors and intestinal motility. Fundam Clin Pharmacol 1995;9:332-342.

19. Arch JR, Ainsworth AT, Cawthorne MA, Piercy V, Sennitt MV, Thody VE, Wilson C, Wilson S. Atypical beta-adrenoceptor on brown adipocytes as target for anti-obesity drugs. Nature 1984;309:163-165.
20. Brown KJ, Summers RJ. Beta(1)- and beta(3)-adrenoceptor mediated smooth muscle relaxation in hypothyroid rat ileum. Eur J Pharmacol 2001;415:257-263.

21. Horinouchi T, Koike K. Functional identification of beta $3-$ adrenoceptors in the guinea-pig ileum using the non-selective beta-adrenoceptor antagonist (+/-)-bupranolol. J Auton Pharmacol 2000;20:253-258.

22. Balsiger BM, Duenes JA, Ohtani N, Shibata C, Farrugia G, Anding WJ, Sarr MG. Nitric oxide pathways in circular muscle of the rat jejunum before and after small bowel transplantation. J Gastrointest Surg 2000;4:86-92.

23. Balsiger BM, Ohtani N, Anding WJ, Duenes JA, Sarr MG. Chronic extrinsic denervation after small bowel transplantation in rat jejunum: Effects and adaptation in nitrergic and non-nitrergic neuromuscular inhibitory mechanisms. Surgery 2001;129:478-489.

24. Balsiger BM, He CL, Zyromski NJ, Sarr MG. Neuronal adrenergic and muscular cholinergic contractile hypersensitivity in canine jejunum after extrinsic denervation. J Gastrointest SuRG 2003;7:572-582.

25. Ozturk Y, Yildizoglu-Ari N, Ozuari A, Ozcelikay AT, Altan VM. Decreased beta-adrenergic responses of rat small intestine due to non-insulin-dependent diabetes. Diabetes Res Clin Pract 1990;9:123-127.

26. Manara L, Croci T, Aureggi G, Guagnini F, Maffrand JP, Le Fur G, Mukenge S, Ferla G. Functional assessment of beta adrenoceptor subtypes in human colonic circular and longitudinal (taenia coli) smooth muscle. Gut 2000;47:337342.

27. Hutchinson DS, Evans BA, Summers RJ. Beta(1)-adrenoceptors compensate for beta(3)-adrenoceptors in ileum from beta(3)-adrenoceptor knock-out mice. Br J Pharmacol 2001; 132:433-442.

28. Susulic VS, Frederich RC, Lawitts J, Tozzo E, Kahn BB, Harper ME, Himms-Hagen J, Flier JS, Lowell BB. Targeted disruption of the beta 3 -adrenergic receptor gene. J Biol Chem 1995;270:29483-29492.

29. Anthony A. Review article: Beta 3-adrenoceptor agonistsfuture anti-inflammatory drugs for the gastrointestinal tract? Aliment Pharmacol Ther 1996;10:859-863.

30. Anthony A, Schepelmann S, Guillaume JL, Strosberg AD, Dhillon AP, Pounder RE, Wakefield AJ. Localization of the beta(beta)3-adrenoceptor in the human gastrointestinal tract: An immunohistochemical study. Aliment Pharmacol Ther 1998;12:519-525. 